\title{
РОЛЬ ОЖИРЕНИЯ В СТРУКТУРЕ НЕВЫНАШИВАНИЯ БЕРЕМЕННОСТИ
}

O жирение и метаболический синдром (MC) актуальны не только с позиции гинекологических проблем, таких как нарушение овариально-менструального цикла, бесплодие, но и в плане прогноза течения, и в плане ведения беременности, родов и послеродового периода [2, 3, 5, 8, 9].

В случае наступления беременности у женщин с ожирением и МС врачи сталкиваются с рядом осложнений: угроза прерывания беременности, зачастую синдром задержки роста плода, возникновение поздних гестозов, вплоть до тяжелой формы эклампсии и гибели плода $[5,6]$. По мнению многих исследователей, ожирение не только взаимосвязано с материнскими и перинатальными исходами, но и является независимым фрактором риска развития перинатальных проблем (гипертензивные нарушения во время беременности, гестационный сахарный диабет, макросомия плода), причиной родоразрешения путем операции кесарево сечение, а также гнойно-септических осложнений после оперативного родоразрешения даже на фоне антибиотикопрофрилактики [1, 3, 4, 6, 7, 9].

Цель исследования заключалась в изучении клинического течения беременности у женщин с повышенной массой тела, а также в анализе степени выраженности ожирения для прогноза вынашивания беременности.

\section{МАТЕРИАЛЫ И МЕТОДЫ ИССЛЕДОВАНИЯ}

Согласно поставленной цели, в исследование вошли 70 беременных женщин с повышенной массой тела или ожирением. Они находились на стационарном лечении по поводу угрозы прерывания беременности в отделении реабилитации репродуктивной функции женщины городского клинического родильного дома № 2 г. Днепропетровска. На сроке беременности 5-6 нед были взяты на учет 56 (80\%) пациенток, 9-10 нед - десять (14,3\%) беременных и на сроке 12-13 нед - четыре (5,7\%) женщины. Все беременные были подвергнуты углубленному обследованию согласно клиническим протоколам МЗ Украины. После стационарного лечения в дальнейшем они наблюдались в женской консультации, где при необходимости им были проведены перинатальные консилиумы.

Распределение тематических беременных на группы проводили с учетом степени ожирения. Ориентиром в этом случае служила масса женщины до наступления беременности. Такое распределение на группы было обосновано тем фактом, что наличие ожирения до беременности связано с повышением риска смерти плода в гестационном периоде.
Согласно рекомендациям по оценке антропометрических данных, определяли рост, массу тела, индекс массы тела (ИМТ).

Всем женщинам, помимо протокола обследования, утвержденного приказом МЗ Украины № 624, с их согласия с помощью иммуноферментного анализа определяли уровень гомоцистеина. Обязательным было выполнение гемостазиограммы с определением волчаночного антикоагулянта.

Некоторые параметры в системе гемостаза изучали определением Д-димера, который является одним из специфичных тестов диагностики тромбофилии и тромбоза, содержания ффибриногена, протромбинового индекса, продуктов деградации фрибрина и фибриногена.

\section{РЕЗУЛЬТАТЫ И ИХ ОБСУЖДЕНИЕ}

Беременные поступали в стационар с жалобами на боль ноющего характера (реже схваткообразного), на кровянистые выделения из половых путей. На невынашивание беременности в анамнезе указывали 56 (80\%) пациенток: $19(79,2 \%)$ женщин первой клинической группы, 21 (80,8\%) - второй, шесть (75\%) - третьей, десять (83,3\%) - четвертой группы.

Распределение беременных на группы согласно классификации ВОЗ приведено в таблице.

При изучении гормонального профииля выявлены следующие изменения. Так, уровень $\beta$-субъединицы хорионического гонадотропина не выходил за пределы нормативных значений, однако приближался к нижней границе нормы у $46(65,7 \%)$ беременных; из них у $13(28,3 \%)$ лиц первой группы, у 18 $(39,1 \%)$ - второй, у семи $(15,2 \%)$ - третьей, у восьми $(17,4 \%)$ - четвертой. Гипопрогестеронемия выявлена у $62(88,6 \%)$ женщин, и лишь у восьми $(11,4 \%)$ пациенток уровень прогестерона в крови соответствовал параметрам нормы. Все восемь вышеуказанных женщин относились к первой тематической группе. Гиперандрогения была выявлена у 51 (72,9\%) беременной.

Эфрфекты прогестерона направлены на поддержание децидуальной оболочки. Недостаток прогестерона приводит к нарушению процессов инвазии. Прогестерон выступает в качестве мощного релаксанта гладкомышечных элементов миометрия, кровеносных сосудов и других органов, обеспечивая их адаптацию к беременности $[5,6]$. В процессе подготовки к имплантации под влиянием прогестерона в эндометрии происходит
3.М. ДУБОССАРСКАЯ

д.мед.н., профессор кафедры акушерства, гинекологии и перинатологии

ФПО ГУ «Днепропетровская медицинская академия

МЗ Украины»

Ю.М. ДУКА

к.мед.н., доцент кафедры акушерства, гинекологии и перинатологии

ФПО ГУ «Днепропетровская медицинская академия МЗ Украины» 
ТАБЛИЦА.

\begin{tabular}{|c|c|c|c|c|}
\hline \multirow{2}{*}{ Степень ожирения } & \multicolumn{3}{|c|}{ Группы } & Четвертая \\
\hline & Первая & Вторая & Третья & 0жирение III степени \\
\hline ИМТ, кг/M² & Избыточная масса тела & Ожирение I степени & Ожирение II степени & $>40$ \\
\hline К-во женщин (процент от & $25-29,9$ & $30-34,9$ & $35-39,9$ & $12(1,7 \%)$ \\
общего числа наблюдений) & $24(34,3 \%)$ & $26(37,1 \%)$ & $8(11,4 \%)$ & \\
\hline
\end{tabular}

ТАБЛИЦА.

РАСПРЕДЕЛЕНИЕ БЕРЕМЕННЫХ НА ГРУППЫ повышение содержания ингибитора активации плазминогена типа 1 (PAІ-1), тканевого фрактора и снижение уровня активатора плазмина тканевого и урокиназного типов, металлопротеаз матрикса и вазоконстриктора - эндотелина 1. Эта физиологическая регуляция гемостаза, фибринолиза, экстрацеллюлярного матрикса и сосудистого тонуса направлена на предотвращение образования геморрагии при дальнейшей инвазии трофробласта. Со своей стороны бластоциста синтезирует активаторы плазминогена тканевого и урокиназного типов и протеазы, необходимые для разрушения экстрацеллюлярного матрикса в процессе имплантации. Их синтез в свою очередь регулируется хорионическим гонадотропином [5-7].

Помимо этого, при нормальном содержании прогестерона происходит взаимодействие с киллер-ингибирующими рецепторами через прогестерон-индуцирующий блокирующий фактор (РІВР), что приводит к активации иммунного ответа матери через систему Т-хелперов ॥ типа (Th II). Th II продуцируют регуляторные цитокины - интерлейкины (ИЛ): ИЛ-3, ИЛ-4, ИЛ-10. Регуляторное действие ИЛ-3 в период имплантации определяет пролиферативную активность цитотрофобласта и фибринолитические процессы в эндометрии (за счет активации урокиназы, превращающей плазминоген в плазмин). Прогестерон посредством Th II и ИЛ-3 влияет также на локальные механизмы гемостаза в эндометрии. РІВР стимулирует защиту эндометрия от отторжения эмбриона. При низком содержании прогестерона вырабатывается мало РІВР и происходит активация натуральных киллеров. Клетки трофобласта не резистентны к лизису активированными NK-клетками (натуральными киллерами) [5-7].

Подтверждением вышесказанному были результаты УЗИ. При УЗИ у 39 (55,7\%) беременной выявлена супрацервикальная локализация ретрохориальной гематомы, у $22(31,4 \%)$ пациенток расположение гематомы было корпоральным. В девяти (12,9\%) наблюдениях боль внизу живота была единственным клиническим проявлением, 11 (31,4\%) пациенток предъявляли жалобы лишь на кровянистые выделения из половых путей, и в 38 (54,3\%) случаях имело место сочетание боли и кровянистых выделений различной интенсивности. Следует отметить, что в $33(67,3 \%)$ из 49 случаев кровянистыми выделениями проявлялась супрацервикальная гематома. Сочетание боли и кровянистых выделений было примерно равным: при корпоральном расположении в 12 (54,5\%) наблюдениях, при супрацервикальной локализации - в 26 (66,6\%) случаях. Объем гематомы рассчитывался по формуле: $V=\left(L_{1} \times L_{2} \times L_{3}\right) / 2$, где $L_{1}, L_{2}, L_{3}$ - длина, ширина и переднезадний размеры гематомы. Объем гематомы колебался в пределах от 0,29 до 41,5 $\mathrm{cm}^{3}$ и в среднем составил 6,8 $\pm 6,3 \mathrm{~cm}^{3}$. При проведении исследования также оценивали тонус матки: в 24 (34,3\%) случаях тонус матки был нормальным, в остальных наблюдениях отмечался гипертонус. При измерении длины шейки матки изменений не выявлено, в среднем она составила 35,6 + 3,4 мм. Средний диаметр желточного мешка - 4,3 \pm 0,6 мм, его структура была без изменений. Объемы хориальной и амниальной полостей соответствовали сроку беременности. При эхографии желтого тела яичника определяли его форму, структуру, толщину периферического контура и характер васкуляризации. Во всех наблюдениях форма желтого тела была округлой, средний диаметр составил $21 \pm 3,9$ мм, ширина периферического контура $-3,9 \pm 1,1$ мм.

По результатам исследования системы гемостаза выявили гиперкоагуляционный синдром за счет повышения активности фракторов внутреннего пути свертывания и повышения функциональной активности тромбоцитов у 45 (64,3\%) женщин; у 25 $(35,7 \%)$ - существенные нарушения в системе протеина $\mathrm{C}$.

Гиперфибриногенемия обнаружена у 57 $(81,4 \%)$ беременных. Причем по мере повышения ИМТ показатель уровня фиириногена тоже повышался. Это подтверждает доказанный фракт того, что гиперфибриногенемия является составляющей MC наравне с гипертриглицеридемией и гиперинсулинемией.

Уровень Д-димера превышал нормативные значения в среднем в 2-3 раза, начиная с I триместра беременности и составил: $0,9 \pm 0,25$ мкгФЕО/мл у женщин первой группы; 1,2 2 0,37 мкгФЕО/мл - второй; 1,5 \pm 0,41 мкгФЕО/мЛ - третьей; 2,1 \pm 0,52 мкгФЕО/ мл - у пациенток четвертой клинической группы. Отмечалась прямая корреляционная зависимость между уровнем Д-димера и степенью ожирения у беременных. 
Гипергомоцистеинемия выявлена у 32 (45,7\%) пациенток; циркуляция волчаночного антикоагулянта - в $26(37,1 \%)$ случаях.

Всем пациенткам проводили комплексную сохраняющую терапию согласно клиническому протоколу Приказа МЗ Украины № 624 «Невынашивание беременности». При доказанной прогестероновой недостаточности назначали препарат утрожестан в дозе от 100 до 400 мг/ сут. Утрожестан обладает антиандрогенным эфффектом, не влияет отрицательно на систему гемостаза, не оказывает негативного воздействия на уровень артериального давления, на углеводный и липидный обмен. Вышеуказанные свойства делают утрожестан препаратом выбора в лечении гипопрогестеронемии у женщин с ожирением $[6,7]$.

При проведении гемостатической терапии препаратом выбора был транексам. Применение транексама играет двоякую роль: с одной стороны, происходит организация гематомы, с другой - снижается уровень деградации фрибрина и фибриногена, которые образуются в больших количествах в условиях возникновения гематомы и обладают прямым повреждающим действием на плод. Дополнительным аргументом к назначению транексама служит его противовоспалительный эффрект [7]. Однако не следует забывать, что при длительном применении препарата у пациенток с высоким риском развития тромбоэмболических осложнений он потенциально опасен, поскольку может повышать риск возникновения тромбозов. Транексам назначали по 500 мг 2 раза в день в течение не более 5-7 сут.

В восьми $(11,4 \%)$ наблюдениях произошел самопроизвольный выкидыш в I триместре беременности. В этих случаях имел место большой объем гематомы. У 62 (88,6\%) пациенток беременность прогрессировала.

При выявлении гиперкоагуляционного синдрома после стабилизации состояния гематомы, назначали низкомолекулярные гепарины (НМГ), так как это была та самая клиническая ситуация, когда показания к применению НМГ имеются, а условий для их применения нет. В таком случае все лечебные мероприятия должны быть вначале направлены на быстрейшую организацию гематомы, снижение тонуса матки и гормональную поддержку беременности.

Дозу НМГ у пациенток с микротромбозами подбирали индивидуально, в зависимости от уровня молекулярных маркеров тромбофилии, а именно Д-димера. Обязательным было мониторирование числа тромбоцитов.

ВЫвОДЫ

1. Десицит прогестерона у женщин с ожирением и МС может привести к нарушению процессов инвазии трофобласта, имплантации, а следовательно и к синдрому потери плода. Дисфункция плаценты у лиц с ожирением главный фрактор, приводящий к гибели плода.
2. При угрозе прерывания беременности, осложнившейся отслойкой хориона с образованием внутриматочной гематомы, необходимо учитывать локализацию, объем гематомы, оценивать состояние экстраэмбриональных структур, желтого тела яичника, его васкуляризацию для выбора рациональной тактики ведения беременности.

3. При назначении НМГ на ранних сроках беременности, благодаря их антикоагулянтным, а также и многим биологическим эфрфектам, улучшаются процессы имплантации, инвазии трофобласта и плацентации; на более поздних сроках они предотвращают тромбирование сосудов плаценты и макротромбозы у матери.

Список литературы в количестве 9 источников представлен на сайте www.reproduct-endo.com.ua

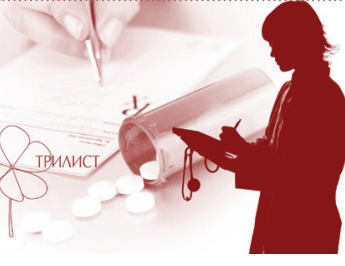

У беременных с ожирением десицит прогестерона обусловливает дисфункцию плаценты, что приводит к гибели плода 